\title{
Empowering Patients Living With Chronic Conditions Using Video as an Educational Tool: Scoping Review
}

\author{
Olga Navarro ${ }^{1,2}$; Marta Escrivá ${ }^{1}$; Raquel Faubel ${ }^{3,4,5}$, PhD; Vicente Traver $^{2,4}$, PhD \\ ${ }_{1}^{1}$ Department of Nursing, Catholic University of Valencia, Valencia, Spain \\ ${ }^{2}$ Institute of Information and Communication Technologies, Universitat Politècnica de València, Valencia, Spain \\ ${ }^{3}$ Department of Physiotherapy, Universitat de València, Valencia, Spain \\ ${ }^{4}$ Unidad Mixta de Reingeniería de Procesos Sociosanitarios, IIS La Fe-Universitat Politècnica de València, Valencia, Spain \\ ${ }^{5}$ Physiotherapy in Motion, Multispeciality Research Group, Department of Physiotherapy, Universitat de València, Valencia, Spain
}

\section{Corresponding Author:}

Raquel Faubel, PhD

Department of Physiotherapy

Universitat de València

Gascó Oliag 5

Valencia, 46010

Spain

Phone: 34963983853

Email: raquel.faubel@uv.es

\section{Abstract}

Background: Video is used daily for various purposes, such as leisure, culture, and even learning. Currently, video is a tool that is available to a large part of the population and is simple to use. This audio-visual format has many advantages such as its low cost, speed of dissemination, and possible interaction between users. For these reasons, it is a tool with high dissemination and educational potential, which could be used in the field of health for learning about and management of chronic diseases by adult patients.

Objective: The following review determines whether the use of health educational videos by adult patients with chronic diseases is effective for their self-management according to the literature.

Methods: An electronic literature search of the PubMed, CINAHL, and MEDLINE (via the EBSCOhost platform) databases up to April 2020 was conducted. The systematic scoping review followed the Preferred Reporting Items for Systematic reviews and Meta-Analysis (PRISMA) methodology.

Results: After reviewing 1427 articles, 12 were selected as the most consistent with the proposed inclusion criteria. After their review, it was found that the studies showed that video is effective as a tool for improving care related to chronic diseases.

Conclusions: Video is effective in improving the care and quality of life for patients with chronic diseases, whether the initiative for using video came from their health care professionals or themselves.

(J Med Internet Res 2021;23(7):e26427) doi: $\underline{10.2196 / 26427}$

\section{KEYWORDS}

patients; health education; self-care; video; chronic disease

\section{Introduction}

\section{Overview}

The increase in the use of social networks and the need for patients to know more about their disease or that of a loved one and how to manage it properly have led to calls for the health system to be updated and health professionals to offer patients reliable and quality tools. Video has become a powerful teaching and dissemination method in all fields. In the health field, it is also used for educational and empowering purposes for the patient, especially when the patient has a chronic disease.

By supplying educational videos for viewing in the health field, the aim is to help patients improve their quality of life through more rigorous self-care, encouraging their access to the health system and often, making personalized care available if video enables live video conferences with health care professionals. 
Video is a very useful and effective tool, both for professionals and patients, due to its low cost, speed of dissemination, and ease of access.

\section{Background}

The annual report "The Global State of Digital in 2019" created by Hootsuite and We Are Social [1] positioned the YouTube audio-visual platform as the most used social network in Spanish-speaking countries (Mexico, Colombia, Argentina, and Spain). In Spain, 89\% of social network users use YouTube [2]. One of the characteristics of the videosocial networks (eg, YouTube or Vimeo) is that the shared videos can host comments and these are registered publicly; in this way, a question that a person asks publicly can be read by other users who have a similar question. This feature, together with its enormous popularity, makes it a tool worth considering for disseminating health information $[3,4]$.

Numerous studies consider that online video content on health is useful and highly effective for educating patients [5,6], although others point out that this content should be viewed with caution since it could be erroneous or confusing and not provide quality information [7-10]. In fact, the most popular videos or those with the highest number of views may contain low-quality or even inappropriate content.

For this reason, many researchers agree on the need for professionals to lead the creation of quality video content [4], although it could also be helpful for patients to do so [11].
It is important to bear in mind that YouTube or Vimeo have their own algorithm for classifying videos that are published, so that, despite efforts from professionals or institutions to generate quality videos, such videos may not reach the target public if they are not properly disseminated and other approaches are not used [12]. Given the lack of quality or patient-specific content on generalist platforms such as YouTube and Vimeo, the main role of the health professional should be that of content curator or link supplier, helping patients to select quality resources $[13,14]$.

The objective of this scoping review is to determine whether the use of educational videos in the health field for self-management of chronic diseases by adult patients is effective.

\section{Methods}

This study follows the guidelines of the Preferred Reporting Items for Systematic reviews and Meta-Analysis (PRISMA) [15]. The PICO (Patient, Intervention, Comparison, Outcomes) framework was used to answer the question: "Does access to audio-visual tools improve the care of patients and/or their families as a way of empowering them to face up to their pathologies?" as shown in Table 1 .

Table 1. The PICO (Patient, Intervention, Comparison, Outcomes) framework.

\begin{tabular}{lll}
\hline PICO framework & Description & Application to this study \\
\hline $\mathrm{P}$ & $\begin{array}{l}\text { Definition of the problem or patient } \\
\text { I }\end{array}$ & $\begin{array}{l}\text { Adult population with chronic diseases or their adult caregivers } \\
\text { Using video to obtain information about their own illness or a family member's illness }\end{array}$ \\
$\mathrm{C}$ & $\begin{array}{l}\text { Comparison } \\
\text { The effectiveness of viewing videos to improve the care of the chronic pathology to be } \\
\text { treated }\end{array}$ \\
Outcomes $=$ & $\begin{array}{l}\text { Management of chronic disease in adult patient after the use of video as an educational } \\
\text { tool. }\end{array}$
\end{tabular}

The search for journal articles used for this bibliographic review was carried out in the following databases: CINAHL and MEDLINE (via the EBSCOhost platform) and PubMed. The search terms proposed in the process of searching and selecting articles in both databases and the results obtained, in the form of articles, respectively, are shown in the following paragraphs.

The following keywords (MESH descriptors) were used to search for articles: patients, adult, young adult, family, education, health education, self-care, power (psychological), audio-visual aids, video recording, webcasts, chronic disease, chronic pain, caregivers, nursing models. The keywords in Spanish (DECS descriptors) were the following: Pacientes, paciente crónico, familia, cuidadores, educación, autocuidado, vídeo, enfermería, audiovisual, tratamiento, empoderamiento.
To perform this bibliographic review, we selected articles using the following inclusion criteria: articles published between the years 2017 and 2020 (both included); articles dealing with chronic diseases, adult patients, or caregivers; articles where audio-visual content is the main educational tool; studies carried out in humans; text in English and Spanish. All types of sources (academic publications, book publications, reports, and dissertations) included in these databases were accepted. Concerning exclusion criteria, articles on acute diseases or those conducted with pediatric patients were excluded.

As shown in the PRISMA flow diagram (Figure 1), after the initial search and eliminating duplicates, 1415 articles were identified, of which 1387 were eliminated after reading the title and summary. Of the 41 remaining, after critical reading of the complete text, 29 other articles were rejected, and 12 studies were finally selected for inclusion in the scoping review. 
Figure 1. Results of the study selection process using the Preferred Reporting Items for Systematic reviews and Meta-Analysis (PRISMA) methodology.

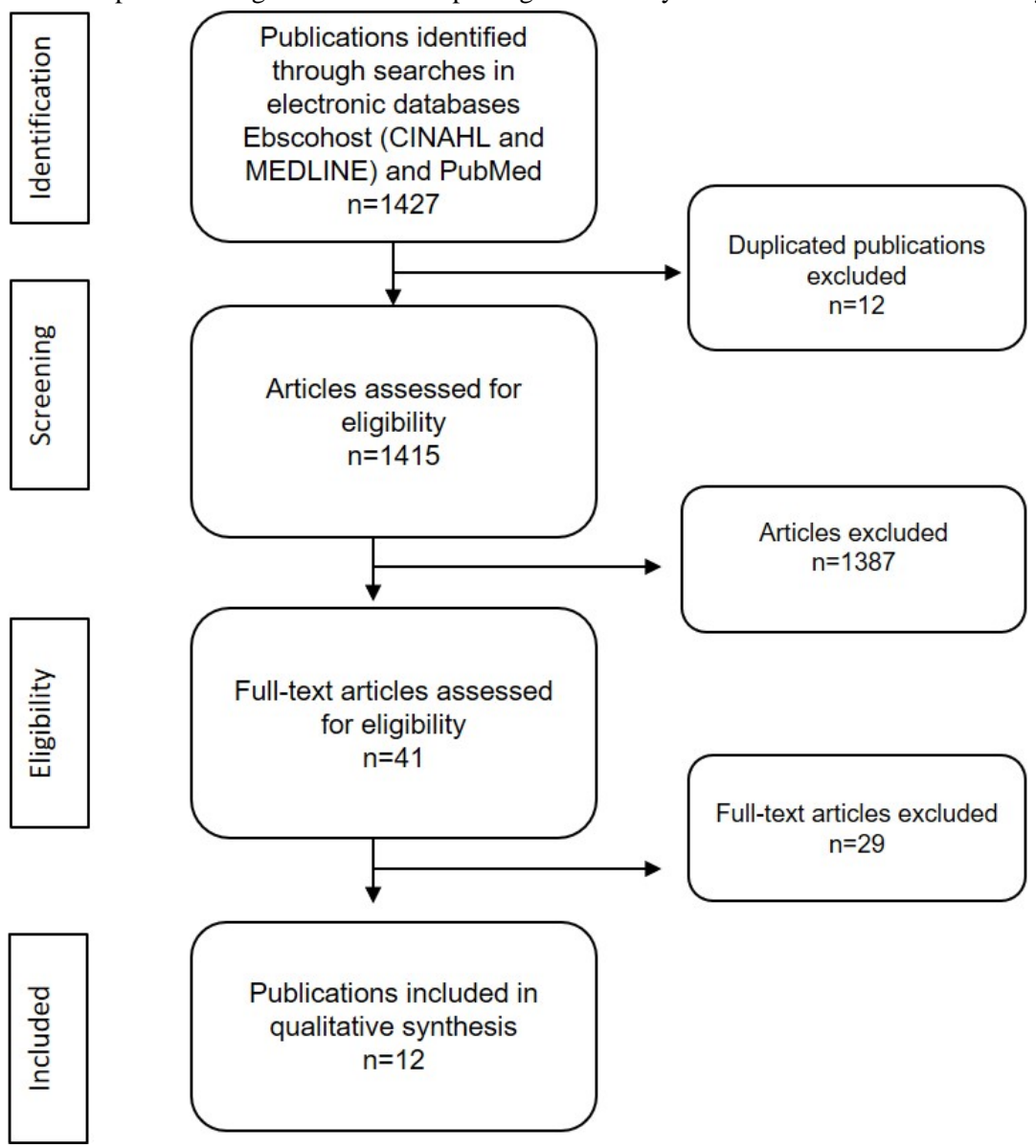

Methodological quality was assessed using the Downs and Black Checklist for Quality Assessment [16] in the modified version used in several previous studies [17-19]. This checklist is made up of a total of 27 questions classified in 4 domains (reporting, external validity, internal validity, and power). Scores on the modified Downs and Black checklist were classified as "excellent" (score 24-28), "good" (19-23), "fair" (14-18), or "poor" $(\leq 13)$.

Relevant data regarding study design, characteristics of participants including chronic disease, and interventions carried out including characteristics of the video used as an educational tool were extracted. Specifically, regarding video characteristics, information was collected about the source of the video (created ad hoc for the study or already existing videos) and how it was used as an educational tool (self-administered, shown during an outpatient visit, or shown during a video conference in a synchronous form). Information about results was also extracted related to the expected results previously described in each study. Positive results were considered when a significant improvement in the objectives proposed for the study for the educational tool was shown.

\section{Results}

In the 12 studies selected to carried out this study, a total of 1398 participants were included. The sample size of the different studies ranged from 8 participants [20] to 429 participants [21], with an average size of 116.5 participants per study. Of the 12 studies, 8 studies included more than 50 subjects. Table 2 summarizes the most relevant data from the articles included. 
Table 2. Descriptive characteristics of the included studies.

\begin{tabular}{|c|c|c|c|c|c|c|}
\hline $\begin{array}{l}\text { Author(s), } \\
\text { year }\end{array}$ & Title or objective & Study design & Participants & Intervention & Results & $\begin{array}{l}\text { Downs and } \\
\text { Black } \\
\text { Checklist } \\
\text { score }\end{array}$ \\
\hline
\end{tabular}

\begin{tabular}{lll}
\hline Albert et al, & $\begin{array}{l}\text { Factors associated } \\
\text { with telemonitoring } \\
\text { use among patients } \\
\text { with chronic heart } \\
\text { failure }\end{array}$ & $\begin{array}{l}\text { Descriptive } \\
\text { cross- } \\
\text { sectional study }\end{array}$ \\
& & \\
Rosen et al, & $\begin{array}{l}\text { Telehealth protocol } \\
\text { to prevent readmis- } \\
\text { sion among high- } \\
\text { risk patients with } \\
\text { congestive heart } \\
\text { failure }\end{array}$ & \\
& & \\
&
\end{tabular}

Vogler et al, Assessing outcomes 2017 [24] of educational videos in group visits for patients with chronic pain at an academic primary care clinic

FarverVestergaard et al, 2019 [20]

Teledelivered mindfulness-based cognitive therapy in chronic obstructive pulmonary disease: a mixed methods feasibility study

Ward et al, Evaluation of multi2018 [25] disciplinary pulmonary rehabilitation education delivered by either DVD or spoken talk

Ketelaars et The effect of video al, 2017 [26] information on anxiety levels in women attending colposcopy: a randomized controlled trial

De Lep- The effect of an oneleere et al, line video interven2017 [27] $\quad$ tion "movie models" on specific parenting practices and parental self-efficacy related to children's physical activity, screen-time and healthy diet
206 outpatients A 6-minute video was of- The intervention was well and hospitalized fered that dealt with telemon- received by the patients, espatients with itoring, which was intended pecially when satisfying the heart failure to collect information on the personal needs of care and patient's blood pressure and learning in a bidirectional weight to send to the caregiv- way with a doctor or a er. Subsequently, question- nurse, through the use of naires were used to evaluate smartphones. the efficacy.

50 patients with A telehealth platform was congestive heart developed that enables, failure through videoconferencing, educating patients about their disease, to prevent hospital readmissions for congestive heart failure.

Analytical observational prospective cohort study

14 patients with chronic noncancerous pain who underwent an educational program on pain

Quasiexperimen- 8 patients with tal study COPD $^{a}$ underwent Mindfulness-Based Cognitive Therapy through videoconferencing

Analytical observational cohort study

123 patients Educational videos were of cussed orally in a subsequent group visit. In total, there were 4 group visits.

Adherence to treatment was increased, and there was a marked decrease in readmission of patients with congestive heart failure.

score

16 with COPD in a pulmonary rehabilitation study

Two groups underwent mindfulness therapy to reduce psychological distress and improve the physical health of COPD through video conference sessions.

The study participants, by improving their knowledge, reduced the doses of painkillers they took, in addition to reducing visits to the emergency room for pain.

Clinical improvement was observed in hospital depression and anxiety. The patients perceived an improvement in unpleasant physical sensations and psychological symptoms.

Two groups were divided:

Education via DVD was One was provided with edu- found to be as effective as cation about pulmonary reha- traditional education. bilitation through DVD, and the other group received the same information through oral and face-to-face discussion.

Randomized con- 136 women, trolled clinical older than 18 trial years, with a positive hrH$\mathrm{PV}^{\mathrm{b}}$ test, re-

Group A received information about colposcopy through a video and a brochure. Group B was only given the brochure.

The video did not significantly reduce the levels of anxiety, depression, or pain in pants positively valued the video information. poscopy

Quasiexperimental two-arm study

238 parents

The study offered 22 online, Parents valued the video as with children 6 12 years old 2-minute videos on obesity and chronicity prevention for 4 weeks. a useful and applicable tool. It was an effective tool for improving family habits and parental self-efficacy. 


\begin{tabular}{|c|c|c|c|c|c|c|}
\hline $\begin{array}{l}\text { Author(s), } \\
\text { year }\end{array}$ & Title or objective & Study design & Participants & Intervention & Results & $\begin{array}{l}\text { Downs and } \\
\text { Black } \\
\text { Checklist } \\
\text { score }\end{array}$ \\
\hline
\end{tabular}

\begin{tabular}{|c|c|c|c|c|c|c|}
\hline $\begin{array}{l}\text { Bakas et al, } \\
2019 \text { [28] }\end{array}$ & $\begin{array}{l}\text { Using telehealth to } \\
\text { optimize healthy in- } \\
\text { dependent living for } \\
\text { older adults: a feasi- } \\
\text { bility study }\end{array}$ & $\begin{array}{l}\text { Quasiexperimen- } \\
\text { tal study }\end{array}$ & $\begin{array}{l}22 \text { older adults } \\
\text { with some } \\
\text { chronic health } \\
\text { condition }\end{array}$ & $\begin{array}{l}\text { A textbook, advice sheets, } \\
\text { and } 2 \text { DVDs were provided; } \\
3 \text { telepresence sessions were } \\
\text { held where the patients were } \\
\text { trained using the tools pro- } \\
\text { vided. }\end{array}$ & $\begin{array}{l}\text { Improvements were found } \\
\text { in quality of life, self-effica- } \\
\text { cy, and confidence per- } \\
\text { ceived by the patients. }\end{array}$ & 17 \\
\hline $\begin{array}{l}\text { Zanaboni et } \\
\text { al, } 2017 \text { [29] }\end{array}$ & $\begin{array}{l}\text { Long-term exercise } \\
\text { maintenance in } \\
\text { COPD via telereha- } \\
\text { bilitation: a 2-year } \\
\text { pilot study }\end{array}$ & $\begin{array}{l}\text { Quasiexperimen- } \\
\text { tal study }\end{array}$ & $\begin{array}{l}10 \text { adult COPD } \\
\text { patients }\end{array}$ & $\begin{array}{l}\text { The intervention consisted } \\
\text { of providing patients with } \\
\text { exercises at home, super- } \\
\text { vised by videoconference by } \\
\text { a physiotherapist. }\end{array}$ & $\begin{array}{l}\text { It was determined that telere- } \\
\text { habilitation is feasible for } \\
\text { maintaining good long-term } \\
\text { health status in COPD pa- } \\
\text { tients. }\end{array}$ & 20 \\
\hline $\begin{array}{l}\text { Taylor et al, } \\
2018 \text { [30] }\end{array}$ & $\begin{array}{l}\text { Integrating innova- } \\
\text { tive telehealth solu- } \\
\text { tions into an interpro- } \\
\text { fessional team-deliv- } \\
\text { ered chronic care } \\
\text { management pilot } \\
\text { program }\end{array}$ & $\begin{array}{l}\text { Retrospective ob- } \\
\text { servational study }\end{array}$ & $\begin{array}{l}69 \text { patients with } \\
3 \text { or more } \\
\text { chronic patholo- } \\
\text { gies, taking at } \\
\text { least } 5 \text { drugs }\end{array}$ & $\begin{array}{l}\text { A teleconsultation service } \\
\text { was provided with a pharma- } \\
\text { cist to review treatments, } \\
\text { doses, and improve adher- } \\
\text { ence. }\end{array}$ & $\begin{array}{l}\text { One-third of the patients } \\
\text { changed their habits after } \\
\text { pharmaceutical advice. It } \\
\text { was found to be a useful tool } \\
\text { for reducing errors. }\end{array}$ & 15 \\
\hline $\begin{array}{l}\text { McLeod et } \\
\text { al, 2020 [21] }\end{array}$ & $\begin{array}{l}\text { Impact of a compre- } \\
\text { hensive digital } \\
\text { health programme } \\
\text { on HbA1c and } \\
\text { weight after } 12 \\
\text { months for people } \\
\text { with diabetes and } \\
\text { prediabetes: a ran- } \\
\text { domised controlled } \\
\text { trial }\end{array}$ & $\begin{array}{l}\text { Randomized con- } \\
\text { trolled trial }\end{array}$ & $\begin{array}{l}429 \text { patients } \\
\text { with diabetes } \\
\text { not taking in- } \\
\text { sulin and daily } \\
\text { access to the in- } \\
\text { ternet }\end{array}$ & $\begin{array}{l}\text { The control and intervention } \\
\text { arms received usual care. } \\
\text { The intervention arm re- } \\
\text { ceived the BetaMe/Melon } \\
\text { program over } 12 \text { months, } \\
\text { delivered through mobile } \\
\text { devices and web-based plat- } \\
\text { forms. }\end{array}$ & $\begin{array}{l}\text { There were small improve- } \\
\text { ments in } \mathrm{HbA1} \mathrm{c}^{\mathrm{c}} \text { and weight } \\
\text { at } 4 \text { months that had largely } \\
\text { attenuated by } 12 \text { months. } \\
\text { The BetaMe/ } \\
\text { Melon program in its current } \\
\text { form cannot be recommen- } \\
\text { ed } \\
\text { for use in the management } \\
\text { of diabetes or prediabetes. }\end{array}$ & 25 \\
\hline $\begin{array}{l}\text { Locke et al, } \\
2019 \text { [31] }\end{array}$ & $\begin{array}{l}\text { Using video tele- } \\
\text { health to facilitate } \\
\text { inhaler training in } \\
\text { rural patients with } \\
\text { obstructive lung dis- } \\
\text { ease }\end{array}$ & $\begin{array}{l}\text { Retrospective ob- } \\
\text { servational analyt- } \\
\text { ical cohort study }\end{array}$ & $\begin{array}{l}93 \text { resident pa- } \\
\text { tients with } \\
\text { COPD or asth- } \\
\text { ma in a rural } \\
\text { setting }\end{array}$ & $\begin{array}{l}\text { Live video training sessions } \\
\text { were given to patients to ex- } \\
\text { plain the use of inhalers. }\end{array}$ & $\begin{array}{l}\text { Improvement in inhalation } \\
\text { technique was achieved by } \\
\text { patients with asthma or } \\
\text { COPD. }\end{array}$ & 19 \\
\hline
\end{tabular}

${ }^{\mathrm{a}} \mathrm{COPD}$ : chronic obstructive pulmonary disease.

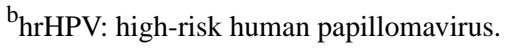

${ }^{\mathrm{c}} \mathrm{HbA1c}$ : glycosylated hemoglobin.

All videos employed as educational tools were specifically created within the frame of research. None of the studies included in the review used public videos or videos already hosted on a YouTube channel.

Regarding the study design, 5 of the studies were designed as a quasiexperimental, pre-post study. Another 5 studies were observational with either a retrospective, prospective, or descriptive design. In those studies, the objective was to assess the impact of videos as an educational tool provided to a group of patients for training or follow-up. Only 2 of the studies were designed as a randomized controlled trial.

Regarding the chronic disease of the participants, the selected studies included participants with diagnoses of chronic obstructive pulmonary disease (COPD; 4/12, 33\%) $[20,25,29,31]$, which was the most frequent; heart failure $(2 / 12$, 17\%) [22,23]; chronic pain $(1 / 12,8 \%)$ [24]; diabetes $(1 / 12,8 \%)$ [21]; or squamous intraepithelial lesion due to human papillomavirus (HPV; 1/12, 8\%) [26]. Participants with any

chronic conditions were included in 3 of the studies [27,28,30], while quality of life was measured in $25 \%$ (3/12) of the studies.

Each study included in the review provided different educational video tools to the subjects who participated in the research: educational video, informative video, video based on real cases, explanatory video. They were provided in different ways and in some cases combined with other educational strategies. Specifically, some studies used videoconferencing to provide physical therapy exercises [29], mindfulness therapy [20], pharmacological advice [30], or training about using inhalers [31]. Other studies used online videos [26,27] for different purposes such as education for pain management [24], information about diagnostic procedures [26], or disease prevention [27]. One study took advantage of an outpatient visit or hospitalization for the patient to view 1 short video about telemonitoring options for their disease [22]. In other studies, videos were provided in a DVD delivered to the patient independently [25] or combined with other activities such as 
videoconference sessions [28]. Lastly, some studies included an educational video combined with other tools incorporated in a complex platform for telehealth [21,23].

These studies assessed whether the application of video had improved the management of chronic disease, and successful results were obtained in most cases. Of the 12 studies included in the review, 2 studies $[21,26]$ did not show significant results to support the hypothesis that video is an effective tool to improve the health of patients with chronic disease in the long term. The study carried out by Ketelaars et al [26] found that the educational video did not significantly reduce the anxiety levels of the participants; that is, it was not effective as a stress reduction tool for women with HPV before a diagnostic procedure, compared with a brochure. However, the patients positively valued the videos offered. On the other hand, McLeod et al [21] found positive results on different outcomes in the first few months of a complex intervention for patients with diabetes. Nevertheless, after 12 months of follow-up, there were no significant differences.

Positive significant results were found in 10 of the 12 studies with a great heterogeneity of outcome variables: The doses of drugs and analgesics [24,30], exacerbations of chronic diseases, readmissions, and emergency room visits [23,24] were all reduced. Studies aimed specifically at patients with COPD showed that rehabilitation using video resources is also effective $[25,29,31]$. In addition to this, studies also found a decrease in pain, anxiety, and depression [20].

Lastly, improvements in disease knowledge [25], satisfaction [27], and health-related quality of life [28] were also found. These data indicate the effectiveness of the audio-visual tools provided to patients for improving management of chronic diseases and reinforcing health advice.

In terms of methodological quality, according to the modified version of the Downs and Black Checklist for Quality Assessment (Multimedia Appendix 1), 7 of the studies presented with a fair quality grade (scores from 15 to 18), and the other 5 studies had excellent or good methodological quality (scores from 19 to 25). The average score was 18.25 . Items with the worst ratings on the quality scale were those related to blinding and randomization.

\section{Discussion}

\section{Principal Findings}

This scoping review identified 1427 articles, of which 12 fulfilled the selection criteria to determine the effectiveness of video as an educational and empowering tool for patients with chronic disease and their caregivers. The results of the review showed that audio-visual instruments are highly effective in the acquisition of competencies by the patient for self-management of chronic diseases. According to the studies reviewed, patients and caregivers themselves were able to improve their self-care and management of chronic diseases after complementing health advice with specific video resources.

In all the articles analyzed in this review, professionals offered the patient or group of patients videos or different audio-visual instruments specifically developed for research. Data on videos freely consulted on the internet by the patient were not included in these articles, nor were different video formats (eg, videoconferencing, DVD viewing, informative or explanatory video, educational video) and their effectiveness compared.

The use of educational videos could contribute to improving the general health status of patients with chronic disease and could even act at a preventive level, reducing the number of admissions and hospital stays. Along these lines, the use of educational videos with adult patients with chronic disease could help reduce anxiety, depression, pain, and even rescue medication doses that patients routinely take.

In addition, educational videos could be a powerful tool for the empowerment of patients with chronic diseases, helping to resolve their issues in a fast, economical, and dynamic way.

It was observed that in all the studies reviewed, health professionals directly offered the video or other audio-visual instruments to a group of patients, and patients did not freely search for videos on the internet. This issue omits investigations where a significant proportion of the population consults and shares videos on the internet, and thus, we were unable to affirm whether in this freer area, not guided by a professional, there are differences in effectiveness.

If audio-visual tools were used in the health system, patients could improve their health status and decrease their admissions and stays in hospital. In addition to this, they could resolve issues wherever they may be, in a fast, economical, and dynamic way.

The implementation of audio-visual tools could reduce the workload of health professionals, reach a greater number of people, decrease health spending, and carry out more effective health education, among other possible benefits.

In this review, in most of the studies, the professionals reinforced the videos with other types of supplementary educational material, such as infographics, brochures, and face-to-face visits.

Despite these results, video is not yet implemented in clinical practice as an educational tool of great value, perhaps due to the scarce evidence in this regard and the lack of training for professionals, among other factors.

Health professionals could have a relevant part in developing or selecting useful and high-quality video material for patients, particularly since videos available via services such as YouTube or Vimeo should be screened by an expert before patients view them, to increase the level of safety and trust in the content [32]. Indeed, material obtained in these video platforms without supervision could even contain dangerous information for patients' health $[33,34]$.

For this reason, it would be useful for health professionals to be updated in the use of new technologies and more specifically video, since audio-visual instruments are highly effective in the management of chronic diseases. Despite this, these tools, in some of the studies that were reviewed, had to be reinforced with additional information that was intelligible by the entire population, including the elderly population. 
Although audio-visual tools are effective for improving the management of pathologies, personalized attention should not be omitted when necessary, so that the combined effectiveness of all educational instruments persists over time and is retained in the population. Good communication between patients and health professionals, either face-to-face or using videoconference, will reduce the need to get additional information. That would avoid browsing video material with low scientific evidence that could be harmful for the patient [35].

The present scoping review was conducted following the PRISMA checklist. Despite this, one of the limitations we found was the low number of articles included in the review and the great heterogeneity in the design of the included studies and chronic diseases included. On the other hand, the methodological quality of some of the studies could be explained by the challenge of recruiting participants for educational research studies and designing randomized controlled trials with a long-term follow-up. At the same time, the diverse range of aspects related to chronicity analyzed in the included studies also represents that using video as an educational and empowering tool for patients with chronic disease could improve several aspects of the disease.

With regard to chronic diseases, after reviewing the 12 selected articles, we concluded that the authors attached great importance to a group of chronic diseases such as COPD, heart disease, and diabetes. On the other hand, there are various chronic diseases that have a high impact on the population and were not included in the studies (eg, hypertension, obesity, fibromyalgia, and dementias); therefore, it would be useful to include them in this type of research. Further possible benefits in the use of video might be found.

On the other hand, the authors suggested tools such as videoconferencing with health care professionals (ie, nurses, doctors, pharmacists) and showed that after use of such tools, significant improvements in patient education are obtained. However, these types of resources are not widely used in health services either. It would be appropriate to study the barriers that hinder the use of these tools when receiving and offering health information through videos, such as lack of expertise in use, lack of technical resources, security, or support problems from the health system.

\section{Conclusions}

Despite the conclusion of the effectiveness of video for educating patients and improving self-care for chronic diseases in different articles published in well-known and high-impact medical journals, the use of video in the health field has not yet been implemented on a routine basis. It would be advisable to continue researching in this area and identify the advantages and benefits that audio-visual instruments can bring to patients with chronic diseases, their caregivers, and health professionals themselves, consolidating video as a complementary tool and of great support in reinforcing the health advice offered in consultations and clinical events.

\section{Acknowledgments}

This study was supported in part by Universidad Católica San Vicente Mártir.

\section{Conflicts of Interest}

None declared.

\section{Multimedia Appendix 1}

Methodological quality according to the modified version of Downs and Black Checklist for Quality Assessment. [DOCX File, $20 \mathrm{~KB}-$ Multimedia Appendix 1]

\section{References}

1. The global state of digital in 2019. Hootsuite. URL: https://www.hootsuite.com/resources/digital-in-2019 [accessed 2021-06-22]

2. Newberry C, Adame A. 22 Estadísticas de YouTube esenciales para este año. Hootsuite. 2019 May 15. URL: https://blog. hootsuite.com/es/estadisticas-de-youtube/ [accessed 2021-06-22]

3. Khatri P, Singh SR, Belani NK, Yeong YL, Lohan R, Lim YW, et al. YouTube as source of information on 2019 novel coronavirus outbreak: a cross sectional study of English and Mandarin content. Travel Med Infect Dis 2020;35:101636 [FREE Full text] [doi: 10.1016/j.tmaid.2020.101636] [Medline: 32205267]

4. Rubel KE, Alwani MM, Nwosu OI, Bandali EH, Shipchandler TZ, Illing EA, et al. Understandability and actionability of audiovisual patient education materials on sinusitis. Int Forum Allergy Rhinol 2020 Apr 12;10(4):564-571. [doi: 10.1002/alr.22518] [Medline: 31930714]

5. Altan Şallı G, Egil E. Are YouTube videos useful as a source of information for oral care of leukemia patients? Quintessence Int 2020;51(1):78-85. [doi: 10.3290/j.qi.a43665] [Medline: $\underline{31781693]}$

6. Ruiz-Roca JA, Martínez-Izquierdo A, Mengual-Pujante D, López EPF, López-Jornet P. Is YouTube a useful tool for oral care in patients with Parkinson's disease? Spec Care Dentist 2020 Sep 06;40(5):464-469. [doi: 10.1111/scd.12489] [Medline: 32628790]

7. Jain N, Abboudi H, Kalic A, Gill F, Al-Hasani H. YouTube as a source of patient information for transrectal ultrasound-guided biopsy of the prostate. Clin Radiol 2019 Jan;74(1):79.e11-79.e14. [doi: 10.1016/j.crad.2018.09.004] [Medline: 30322707] 
8. Cassidy JT, Fitzgerald E, Cassidy ES, Cleary M, Byrne DP, Devitt BM, et al. YouTube provides poor information regarding anterior cruciate ligament injury and reconstruction. Knee Surg Sports Traumatol Arthrosc 2018 Mar 17;26(3):840-845. [doi: 10.1007/s00167-017-4514-x] [Medline: 28314888]

9. Leong AY, Sanghera R, Jhajj J, Desai N, Jammu BS, Makowsky MJ. Is YouTube Useful as a Source of Health Information for Adults With Type 2 Diabetes? A South Asian Perspective. Can J Diabetes 2018 Aug;42(4):395-403.e4. [doi: 10.1016/j.jcjd.2017.10.056] [Medline: 29282200]

10. Lambert K, Mullan J, Mansfield K, Koukomous A, Mesiti L. Evaluation of the quality and health literacy demand of online renal diet information. J Hum Nutr Diet 2017 Oct;30(5):634-645. [doi: 10.1111/jhn.12466] [Medline: 28211108]

11. Salama A, Panoch J, Bandali E, Carroll A, Wiehe S, Downs S, et al. Consulting "Dr. YouTube": an objective evaluation of hypospadias videos on a popular video-sharing website. J Pediatr Urol 2020 Feb;16(1):70.e1-70.e9 [FREE Full text] [doi: 10.1016/j.jpurol.2019.11.011] [Medline: $\underline{\text { 31928900] }}$

12. Fernandez-Llatas C, Traver V, Borras-Morell J, Martinez-Millana A, Karlsen R. Are Health Videos from Hospitals, Health Organizations, and Active Users Available to Health Consumers? An Analysis of Diabetes Health Video Ranking in YouTube. Comput Math Methods Med 2017;2017:8194940-8194949 [FREE Full text] [doi: 10.1155/2017/8194940] [Medline: 28243314]

13. Al-Busaidi IS, Anderson TJ, Alamri Y. Qualitative analysis of Parkinson's disease information on social media: the case of YouTube ${ }^{\mathrm{TM}}$. EPMA J 2017 Sep;8(3):273-277 [FREE Full text] [doi: 10.1007/s13167-017-0113-7] [Medline: 29021838]

14. Lee JL, Frey M, Frey P, Hollin IL, Wu AW. Seeing is Engaging: Vlogs as a Tool for Patient Engagement. Patient 2017 Jun 18;10(3):267-270 [FREE Full text] [doi: 10.1007/s40271-017-0215-2] [Medline: 28101817]

15. Moher D, Shamseer L, Clarke M, Ghersi D, Liberati A, Petticrew M, PRISMA-P Group. Preferred reporting items for systematic review and meta-analysis protocols (PRISMA-P) 2015 statement. Syst Rev 2015 Jan 01;4:1 [FREE Full text] [doi: 10.1186/2046-4053-4-1] [Medline: 25554246]

16. Downs SH, Black N. The feasibility of creating a checklist for the assessment of the methodological quality both of randomised and non-randomised studies of health care interventions. J Epidemiol Community Health 1998 Jun;52(6):377-384 [FREE Full text] [doi: 10.1136/jech.52.6.377] [Medline: 9764259]

17. Trac MH, McArthur E, Jandoc R, Dixon SN, Nash DM, Hackam DG, et al. Macrolide antibiotics and the risk of ventricular arrhythmia in older adults. CMAJ 2016 Apr 19;188(7):E120-E129 [FREE Full text] [doi: 10.1503/cmaj.150901] [Medline: 26903359]

18. Hooper P, Jutai JW, Strong G, Russell-Minda E. Age-related macular degeneration and low-vision rehabilitation: a systematic review. Can J Ophthalmol 2008 Apr;43(2):180-187. [doi: 10.3129/i08-001] [Medline: 18347620]

19. O'Connor SR, Tully MA, Ryan B, Bradley JM, Baxter GD, McDonough SM. Failure of a numerical quality assessment scale to identify potential risk of bias in a systematic review: a comparison study. BMC Res Notes 2015 Jun 06;8:224 [FREE Full text] [doi: $\underline{10.1186 / \mathrm{s} 13104-015-1181-1]}$ [Medline: $\underline{26048813}$ ]

20. Farver-Vestergaard I, O’Connor M, Smith NC, Løkke A, Bendstrup E, Zachariae R. Tele-delivered mindfulness-based cognitive therapy in chronic obstructive pulmonary disease: A mixed-methods feasibility study. J Telemed Telecare 2018 Jun 25;25(8):468-475. [doi: 10.1177/1357633x18780563]

21. McLeod M, Stanley J, Signal V, Stairmand J, Thompson D, Henderson K, et al. Impact of a comprehensive digital health programme on $\mathrm{HbA}$ and weight after 12 months for people with diabetes and prediabetes: a randomised controlled trial. Diabetologia 2020 Dec;63(12):2559-2570. [doi: 10.1007/s00125-020-05261-x] [Medline: 32886192]

22. Albert NM, Dinesen B, Spindler H, Southard J, Bena JF, Catz S, et al. Factors associated with telemonitoring use among patients with chronic heart failure. J Telemed Telecare 2017 Feb;23(2):283-291. [doi: 10.1177/1357633X16630444] [Medline: 26869144]

23. Rosen D, McCall JD, Primack BA. Telehealth Protocol to Prevent Readmission Among High-Risk Patients With Congestive Heart Failure. Am J Med 2017 Nov;130(11):1326-1330. [doi: 10.1016/j.amjmed.2017.07.007] [Medline: 28756266]

24. Vogler CN, Sattovia S, Salazar LY, Leung TI, Botchway A. Assessing outcomes of educational videos in group visits for patients with chronic pain at an academic primary care clinic. Postgrad Med 2017 Jun 16;129(5):524-530. [doi: 10.1080/00325481.2017.1324228] [Medline: 28447542]

25. Ward S, Sewell L, Singh S. Evaluation of multidisciplinary pulmonary rehabilitation education delivered by either DVD or spoken talk. Clin Respir J 2018 Nov 25;12(11):2546-2550. [doi: 10.1111/crj.12954] [Medline: 30221825$]$

26. Ketelaars PJW, Buskes MHM, Bosgraaf RP, van Hamont D, Prins JB, Massuger LFAG, et al. The effect of video information on anxiety levels in women attending colposcopy: a randomized controlled trial. Acta Oncol 2017 Dec;56(12):1728-1733. [doi: 10.1080/0284186X.2017.1355108] [Medline: 28760058]

27. De Lepeleere S, De Bourdeaudhuij I, Cardon G, Verloigne M. The effect of an online video intervention 'Movie Models' on specific parenting practices and parental self-efficacy related to children's physical activity, screen-time and healthy diet: a quasi experimental study. BMC Public Health 2017 Apr 27;17(1):366 [FREE Full text] [doi: 10.1186/s12889-017-4264-1] [Medline: 28449658]

28. Bakas T, Sampsel D, Israel J, Chamnikar A, Bodnarik B, Clark JG, et al. Using telehealth to optimize healthy independent living for older adults: A feasibility study. Geriatr Nurs 2018 Sep;39(5):566-573 [FREE Full text] [doi:

10.1016/j.gerinurse.2018.04.002] [Medline: 29804689] 
29. Zanaboni P, Hoaas H, Aarøen Lien L, Hjalmarsen A, Wootton R. Long-term exercise maintenance in COPD via telerehabilitation: a two-year pilot study. J Telemed Telecare 2016 Jul 09;23(1):74-82. [doi: 10.1177/1357633x15625545]

30. Taylor AM, Bingham J, Schussel K, Axon DR, Dickman DJ, Boesen K, et al. Integrating Innovative Telehealth Solutions into an Interprofessional Team-Delivered Chronic Care Management Pilot Program. J Manag Care Spec Pharm 2018 Aug;24(8):813-818. [doi: 10.18553/jmcp.2018.24.8.813] [Medline: 30058982]

31. Locke ER, Thomas RM, Woo DM, Nguyen EHK, Tamanaha BK, Press VG, et al. Using Video Telehealth to Facilitate Inhaler Training in Rural Patients with Obstructive Lung Disease. Telemed J E Health 2019 Mar;25(3):230-236 [FREE Full text] [doi: 10.1089/tmj.2017.0330] [Medline: $\underline{\text { 30016216] }}$

32. Gabarron E, Fernandez-Luque L, Armayones M, Lau AY. Identifying Measures Used for Assessing Quality of YouTube Videos with Patient Health Information: A Review of Current Literature. Interact J Med Res 2013 Feb 28;2(1):e6 [FREE Full text] [doi: 10.2196/ijmr.2465] [Medline: 23612432]

33. Mueller SM, Hongler VNS, Jungo P, Cajacob L, Schwegler S, Steveling EH, et al. Fiction, Falsehoods, and Few Facts: Cross-Sectional Study on the Content-Related Quality of Atopic Eczema-Related Videos on YouTube. J Med Internet Res 2020 Apr 24;22(4):e15599 [FREE Full text] [doi: 10.2196/15599] [Medline: 32329744]

34. Syed-Abdul S, Fernandez-Luque L, Jian W, Li Y, Crain S, Hsu M, et al. Misleading health-related information promoted through video-based social media: anorexia on YouTube. J Med Internet Res 2013 Feb 13;15(2):e30 [FREE Full text] [doi: 10.2196/jmir.2237] [Medline: 23406655]

35. Langford A, Loeb S. Perceived Patient-Provider Communication Quality and Sociodemographic Factors Associated With Watching Health-Related Videos on YouTube: A Cross-Sectional Analysis. J Med Internet Res 2019 May 17;21(5):e13512 [FREE Full text] [doi: 10.2196/13512] [Medline: $\underline{\text { 31102372] }}$

\author{
Abbreviations \\ COPD: Chronic obstructive pulmonary disease \\ HPV: human papillomavirus \\ PICO: Patient, Intervention, Comparison, Outcomes \\ PRISMA: Preferred Reporting Items for Systematic reviews and Meta-Analysis
}

\author{
Edited by R Kukafka; submitted 11.12.20; peer-reviewed by A Langford, V Press; comments to author 06.02.21; revised version \\ received 01.03.21; accepted 06.05.21; published 06.07.21 \\ Please cite as: \\ Navarro $O$, Escrivá $M$, Faubel $R$, Traver $V$ \\ Empowering Patients Living With Chronic Conditions Using Video as an Educational Tool: Scoping Review \\ J Med Internet Res 2021;23(7):e26427 \\ URL: https://www.jmir.org/2021/7/e26427 \\ doi: $10.2196 / 26427$ \\ PMID: 34255671
}

(C)Olga Navarro, Marta Escrivá, Raquel Faubel, Vicente Traver. Originally published in the Journal of Medical Internet Research (https://www.jmir.org), 06.07.2021. This is an open-access article distributed under the terms of the Creative Commons Attribution License (https://creativecommons.org/licenses/by/4.0/), which permits unrestricted use, distribution, and reproduction in any medium, provided the original work, first published in the Journal of Medical Internet Research, is properly cited. The complete bibliographic information, a link to the original publication on https://www.jmir.org/, as well as this copyright and license information must be included. 